\title{
Conflitos e ambiguidades sobre diferença cultural: alguns impactos para a arte- educação pós-moderna e a cultura visual ${ }^{1}$
}

\author{
Raimundo Martins ${ }^{2}$ \\ Pablo Petit Passos Sérvio ${ }^{3}$
}

\section{Resumo}

Apropriando-nos dos textos de jan jagodzinski (2005), Raimundo Martins (2007) e Arthur Efland (2005), confrontamos algumas reflexões sobre conflitos e ambigüidades em jogo nas discussões sobre "diferença cultural". Expandimos esta discussão enfatizando suas conseqüências para orientações teóricas e práticas da arte-educação pós-moderna e da educação para a cultura visual.

Palavras chave: diferença cultural, educação para a cultura visual, arte-educação pósmoderna

\begin{abstract}
Based on the texts of jan jagodzinski (2005), Raimundo Martins (2007) and Efland (2005), we confront some reflexions about conflicts and ambiguities that play a role in the discussions about "cultural difference". We expand this discussion emphasizing its consequences for theoretical and practical orientations for postmodern art education and visual cultural education.
\end{abstract}

Key-words: cultural difference, visual cultural education, postmodern art education.

Diversos são os interesses que aparentemente confluem na defesa da pertinência dos discursos sobre "diferença cultural", mas é necessário ressaltar que tais discursos não são idênticos ou congruentes. É possível encontrarmos diferentes esquemas de respostas para as questões envolvendo este tema (HALL, 2006; SEMPRINI, 1999; MCLAREN, 2003; MATHIAS, 2006). Segundo Peter McLaren (2003), isto se dá como conseqüência do fato de que a noção de diferença é um produto da história, da cultura, de embates simbólicos entre grupos que lutam em desigualdade de poder, ou seja, o que está em jogo é justamente o que vem a ser a diferença. Assim, podemos afirmar que a palavra "diferença" e, em especial, as imagens que se relacionam a ela são lugares políticos estratégicos na contemporaneidade.

\footnotetext{
${ }^{1}$ Este artigo é parte de investigação em desenvolvimento, inserida na Linha de Pesquisa "Culturas da imagem e processos de mediação" do Programa de Pós-Graduação em Cultura Visual, Mestrado, Faculdade de Artes Visuais, Universidade Federal de Goiás.

2 Doutor em Educação/Artes pela Southern Illinois University (EUA), pós-doutor pela Universidade de Londres (Inglaterra) e pela Universidade de Barcelona (Espanha) onde também foi professor visitante. É Professor Titular e Diretor da Faculdade de Artes Visuais, docente do Programa de Pós-Graduação em Cultura Visual da Universidade Federal de Goiás.

${ }^{3}$ Bolsista Capes no Programa de Pós-Graduação em Cultura Visual-Mestrado da Faculdade de Artes Visuais da Universidade Federal de Goiás, é Especialista em Teoria da Comunicação da Imagem pela Universidade Federal do Ceará e graduado em Comunicação Social (Publicidade e Propaganda) pelo Centro de Ensino Unificado de Teresina, Piauí.
} 
A arte-educação pós-moderna e a educação para a cultura visual são exemplos de campos nos quais e entre os quais se movem interesses para prescrever do que se trata quando se fala de diferença, qual o seu valor e qual deve ser nossa conduta quando encaramos este tema no nosso dia-a-dia. Assim, esses campos servem à observação dos conflitos e ambigüidades resultantes dessas dinâmicas.

Neste artigo propomos reflexões sobre tais conflitos e ambigüidades a partir da discussão de três textos vinculados a estas áreas nos quais seus autores discutem, cada um à sua maneira, concepções de cultura, de diferença cultural e de impactos destes temas sobre a prática de seus campos. Os textos são: As negociações da diferença: arte educação como desfiliação na era pós-moderna, de jan jagodzinski (2005); A cultura visual e a construção social da arte, da imagem e das práticas do ver, de Raimundo Martins (2007), e Cultura, sociedade, arte e educação num mundo pós-moderno, de Arthur Efland (2005). Organizamos esta reflexão em quatro partes assim denominadas: 1) diferentes diferenças, 2) diferentes imagens, 3) diferentes interpretações, e 4) diferentes condutas. $\mathrm{Na}$ primeira, discutimos os interesses em jogo nas distintas conceituações da idéia de cultura e, conseqüentemente, da idéia de diferença cultural; na segunda, debatemos sobre como a discussão sobre diferença cultural provoca a subversão da idéia de arte em favor da inclusão de imagens que hoje estão fora dos cânones institucionais; na terceira, examinamos a relação entre diferença cultural e a necessidade de percebermos a interpretação como momento ativo de negociação e criação cultural; e, por último, na quarta parte, colocamos em perspectiva o modo como a diferença cultural nos impele a pensar sobre a natureza ideológica de toda ação educativa nos forçando a questionar sua responsabilidade (o que podemos falar?), legitimidade (por quem podemos falar?) e abrangência (global ou local).

Antes de iniciarmos este percurso é necessário revelar a posição de onde falamos destacando a concepção de cultura sob a qual, em especial, analisamos essas discussões sobre diferença cultural. Consideramos cultura como processos de significação ou, segundo Canclini (2005), como "conjunto de processos sociais de produção, circulação e consumo da significação na vida social" (p. 41). Sobre esta conceituação o autor explica que:

Ao conceituar a cultura desse modo, estamos dizendo que a cultura não é apenas um conjunto de obras de arte ou de livros e muito menos uma soma de objetos materiais carregados de signos e símbolos. A cultura apresenta-se como processos sociais, e parte da dificuldade de falar dela deriva do fato de que se produz, circula e se consome na história social. Não é algo que apareça sempre da mesma maneira. Daí a importância que adquiriram os estudos sobre recepção e apropriação de bens e mensagens nas sociedades contemporâneas. Mostram como um mesmo objeto 
pode transformar-se através de usos e reapropriações sociais. E também como, ao nos relacionarmos uns com os outros, aprendemos a ser interculturais. (2005, p.41-42)

A preferência por esta concepção de cunho sócio-cultural, cujo foco é as práticas ou as ações de significação, de dar sentido, e não a idéia de sistema, permite falarmos do cultural como uma dimensão fronteiriça, conflitiva, ambígua, nunca harmônica ou homogênea. Ressaltamos que não temos, neste momento, o objetivo de prescrever uma concepção mais correta para a palavra cultura: apenas assumimos uma perspectiva de onde primordialmente examinamos as discussões sobre diferença cultural. Esperamos, ao explicitar este olhar teórico, também permitir, com o decorrer da discussão a seguir, uma visão crítica da natureza política das idéias de cultura.

\section{Diferentes diferenças ou Como tratar da diferença? Que diferença é essa?}

Tanto jagodzinski quanto Efland citam a dificuldade de se trabalhar com a idéia de diferença cultural na sala de aula. Segundo os autores, é comum o depoimento de professores sobre o medo de enfatizarem "diferenças ao invés de similaridades" e com isso enfraquecerem o "consenso social" (EFLAND, 2005, p.176) e/ou "reforçarem preconceitos" (JAGODZINSKI, 2005, p. 680). Nesta postura percebemos o mesmo receio que os defensores da noção de cultura como civilidade guardam em relação à diferença "uma doutrina reacionária que negava a igualdade à qual todos os homens e mulheres tinham direito" (EAGLETON, 2005, p.48-49). A idéia de diferença confunde-se aqui amplamente com barbárie ou desigualdade, de modo que omiti-la ou apagá-la são opções de conduta consideradas adequadas.

Também entre aqueles que valorizam e incluem a "diferença cultural" no campo da arteeducação podemos perceber uma variedade de posturas que estão diretamente relacionadas a distintas leituras das noções de cultura, identidade e diferença. Jagodzinski (2005) cita a abordagem conservadora de arte-educação na qual a diferença é inserida de forma policiada, não ameaçadora, sem questionar a hegemonia ocidental da História da Arte, mas apenas como adição à estrutura curricular tradicional. Esta abordagem ao tratar a diferença, situa as "artes per se" se valendo das "típicas divisões eurocêntricas, ou seja, história da arte islâmica, história da arte oriental, história da arte contemporânea do século XX" (JAGODZINSKI, 2005, p. 681). Ainda segundo o autor:

Para incluir a sua 'arte' dentro das salas de aula existentes são criadas certas marcas identificáveis de diferença estereotipada, idiomas raciais e sistemas semióticos de representação, que pressupõem e afirmam tipificações reguladoras e estereótipos culturais, tornando as culturas nativas e povos não-brancos e não- 
ocidentais identificáveis e utilizáveis em salas de aula. (idem, p. $665)$.

Contra esta tendência que em grande medida isola a arte dos demais setores sociais em uma bolha autônoma (JAGODIZINSKI, 2005), Efland (2005) defende a necessidade de conceitos de cultura que possam incluir aspectos não eruditos. Entretanto, ampliar a noção de cultura da sua interpretação restrita ao mundo das artes a uma noção mais ampla que inclua, por exemplo, as manifestações folclóricas ou as tradições populares, não acompanha necessariamente um uso mais complexo e questionador da idéia de diferença. É o que ocorre quando a diferença é interpretada "como uma 'variação' (diversidade) benigna e como uma simples 'constatação'" (JAGODZINSKI, 2005, p. 664), uma vez que se interpreta a diferença cultural através da lógica da identidade, ou seja, como uma variedade de unidades com leis próprias, instintivas e autônomas umas em relação às outras. Como conseqüência direta, o critério de "autenticidade", ou, em outras palavras, a "pureza", da identidade cultural, considerando os estereótipos prescritos pelas forças hegemônicas ocidentais, acaba colocando/situando "vários 'contemporâneos etnográficos' não-brancos e não-ocidentais num passado congelado" (JAGODZINSKI, 2005, p. 665). Essa concepção de cultura acaba prejudicando especialmente artistas não euro-americanos que são forçados a produzir "arte étnica", ao passo que, contraditoriamente, aos artistas ocidentais (euro-americanos) é permitido "pesquisar outras culturas, enriquecendo desse modo o seu próprio trabalho e as suas perspectivas" (JAGODZINSKI, 2005, p. 666). Aqueles que se negam a reger-se por esta lógica, diz Jagodzinski(2005):

...são apontados como não sendo 'suficientemente autênticos', ou se não estão em conformidade com a separação da divisão entre pré-moderno e moderno, a sua arte é criticada por ser inautenticamente 'ocidentalizada'; colocando-se de maneira simples: eles são acusados de imitadores ou de copiadores. Não há diálogo entre culturas, somente apropriação por artistas de cor. O universal é 'nosso', o local é 'deles', repete essa estrutura liberal (p. 666).

Tentando retirar da idéia de diferença cultural a lógica da identidade, ou seja, de unidade e pureza, jagodzinski (2005) discute duas alternativas que prometeram respostas para a arte-educação. Uma delas é a que podemos chamar de "política de transfiguração", de hibrismo ou cruzamento. Fundamentando-se na consciência de que "não há espaços privilegiados ou fontes simbólicas que possam assegurar autonomia cultural", os defensores desta linha acreditam que toda "identidade é um assunto de contingência política e não ontológica" (p. 671-672), por isso, a atitude mais efetiva contra o racismo seria estar conscientemente sempre se transformando por meio da incorporação da diferença. A segunda alternativa de que nos fala jagodzinski, embora também considere 
a ausência de sentidos naturais para a existência, afasta-se da anterior ao considerar que nem todos detêm as condições necessárias para engajarem-se em um relativismo constante de si. Como nos dizem Robert Stam e Ella Shohat (2006), de fato, muitos não podem se dar ao luxo de se relativizar a esse modo pós-modernista:

Nesse sentido, grande parte da teoria pós-moderna constitui um exemplo sofisticado daquilo que Abdel Malek chama de 'hegemonia das minorias privilegiadas': a negação da realidade da marginalização é um luxo ao qual apenas os indivíduos não marginalizados podem se dar. O centro proclama o fim de seus privilégios precisamente quando a periferia começa a exigi-los. Todas estas distituições refletem um privilégio disponível apenas para quem já tem poder, pois a proclamação do fim das margens não extingue os mecanismos que de fato destituem as pessoas de sua cultura e as nações de seu poder (p. 451).

Terry Eagleton (2005), reitera este posicionamento com a seguinte colocação:

...existe uma diferença importante entre prescindir de essências e fundamentações porque quem você é não é mais uma questão cadente, e prescindir delas quando você precisa de um sentido razoavelmente seguro de quem você é, exatamente com o objetivo de se tornar aquilo que você quer ser. Se você não sabe quem você é no ocidente, o pós-modernismo está à mão para dizer-Ihe para não se preocupar; se você não sabe quem é em áreas menos abastadas do globo, você pode precisar criar as condições em que se torna possível descobrir (p. 111).

Tal perspectiva lembra que quem está em uma posição desigual de poder simbólico se vê forçado a engajar-se em uma luta por uma representação positiva em vez de uma estigmatizada, ou mesmo contra a completa ausência de representação. Para esses muitos, práticas de significação como as políticas de identidade não são algo que se possa abdicar em nome de relativismos totais. Para esses grupos, o idealismo envolvido na criação de comunidades imaginadas é algo que necessitam para se fortalecerem. Por isso, pregam/lutam por um "essencialismo estratégico" (JAGODZINSKI, 2005, p.674) que sirva aos interesses emancipatórios daqueles mantidos em condições de subalternidade.

Como falar, contudo, de essencialismos estratégicos ao mesmo tempo em que se considera "que as culturas nunca são estáticas" (idem, p.676)? Nesse sentido, jagodzinski (idem, p. 679) vê-se forçado a concluir que "tanto o hibridismo como o essencialismo apresentam o seu próprio conjunto de problemas". Por fim, defende que estratégias políticas que visem a emancipação, seja o essencialismo estratégico ou o hibridismo, não podem ser promovidas de modo genérico, mas "devem sempre ser colocadas em termos e condições sócio-históricas" (idem, p. 679). 


\section{Diferentes imagens ou Sobre a necessidade de exceder as fronteiras da arte}

Efland, Martins e jagodzinski, tratam da necessidade de se incluir na sala de aula manifestações visuais além daquelas consideradas artísticas. Contudo, observando as posições de onde falam, é possível notar algumas distinções entre as opiniões desses autores.

Segundo jagodzinski (2005), "a crítica mais radical da diferença", quando este tema é discutido no contexto da arte-educação, deve ser "reconhecer que a 'arte', ela mesma, é um conceito ocidental", "um objeto do discurso filosófico do iluminismo" (p. 671) e, por isso mesmo, precisa ser relativizada e compreendida também como uma construção cultural de um contexto histórico específico. Desconsiderar esta origem ocidental e iluminista da idéia de arte implica comumente a imposição desses critérios às manifestações de culturas outras. Jagodzinski (idem, p. 665) nos fala, por exemplo, de critérios como individualidade e autenticidade que pouco significam para muitas culturas "tradicionais". Assim, uma vez que se percebe as fronteiras ideológicas da arte e as limitações a que condicionam o trabalho dos professores, ele assegura:

[...] uma arte-educação cujos fundamentos permanecem entricheirados na noção de disciplina, no cânone ocidental da arte, no estúdio de arte e nos princípios formalistas de crítica, isto é, o modernismo, tem pouquíssima esperança de realizar algo mais do que a reincorporação de estratégias "neo-racistas" de confinamento (idem, p. 683).

Por tudo isso, o autor propõe então a introdução de três tipos de imagens na sala de aula (p. 685): 1) as do cânone artístico estabelecido; 2) aquelas imagens e artefatos que têm significado especial para tantas culturas quantas forem necessárias e, por fim, 3) imagens da mídia. Quanto a este último item, jagodzinski defende mesmo que imagens da mídia sejam cada vez mais usadas, e Ihe seja dada a maior ênfase, em detrimento dos demais níveis (p. 687).

Martins (2007) também defende este alargamento do campo. Com o foco da cultura visual orientado para as experiências visuais, e não para certas imagens, este campo abandona as antigas distinções entre cultura superior e inferior que permitiam que apenas aqueles objetos cadastrados, considerados objetos das belas artes fossem estudados. Abre-se então à análise de todos os aspectos da vida cotidiana incluindo aqueles que antes foram ignorados, como a cultura midiática. Sobre esta mudança o autor diz:

A ampliação semântica da palavra "arte", para um termo mais abrangente como "visual", implica a perda da auto-referência, da aura fundacional e exclusivista da arte em "favor do conceito mais 
desqualificado da imagem: imagem fílmica, televisiva, artística, virtuais" (Guasch, 2005, p.62). O caráter inclusivo desta dilatação semântica abre espaço para discussão sobre as práticas culturais do ver e suas relações com a subjetividade, reconstruindo o conceito de valor num mundo sitiado por imagens que preenchem e instituem a experiência do cotidiano (MARTINS, 2007, p. 33).

Efland (2005) também trata da necessidade de discutir imagens da mídia. Como jagodzinski e Martins, ele considera que pensar as mídias é necessário, pois estão relacionadas ao cotidiano das pessoas e assim servem para discutirmos a diferença cultural. Contudo, ao contrário dos outros, este autor expressa de forma acintosa um medo, uma certa reserva em relação às imagens midiáticas. Este é o mesmo motivo que o leva a considerá-las. Para Efland, as imagens das mídias não se inserem na sala de aula pelo simples fato de serem imagens tão ideológicas quanto, por exemplo, as imagens artísticas, mas porque representariam um perigo às tradições. Ele diz que,

[...] nos anos vindouros os professores serão forçados a considerar o impacto de sons e imagens para poder, simplesmente, continuar ensinando aquilo que estão acostumados a ensinar, pois as imagens na cultura cotidiana, na TV, em revistas e jornais, criam um impacto direto sobre as crianças: acabam construindo a visão da realidade delas, formando valores e crenças, e isso pode não deixar espaço para imagens de qualquer tipo de cultura tradicional (EFLAND, 2005, p.182).

Apesar de jagodzinski também considerar a importância de analisarmos os preconceitos difundidos pelas mídias, é Efland quem assume uma posição impulsiva no sentido de rotular os produtos midiáticos com palavras como "homogeneizador", "manipulador", "alienante", etc. O autor confessa o medo de que a influência das mídias atinja a "alma" da identidade cultural tradicional das pessoas (idem, p. 181). Então, nos perguntamos: o que seria esta alma? Efland não apresenta fundamentos convincentes ao adotar esta posição e, assim, desenvolve uma análise do seu próprio argumento com pressupostos contraditórios.

O uso do termo "alma" parece sugerir uma visão tradicionalista que confunde cultura com identidade e renega ou, desconsidera, a idéia de que a cultura nunca é estática. Porém, de modo intrigante, neste mesmo texto, Efland, baseando-se em Benjamin Barber, critica este tipo de postura denominando-a "Jihad". O autor faz a seguinte afirmação: "Do ponto de vista da Jihad, a cultura é reduzida aos mitos que mantêm e promovem a identidade tribal, e o estudo de culturas externas pode ser percebido como exposição a influências contaminadoras" (idem, p. 184). A postura da Jihad, segundo Efland, restringiria a liberdade de "explorar o mundo das diferenças para além do 
conjunto de horizontes de sua própria cultura" (idem, p.185). Ocorre que para considerar tal afirmação precisamos nos perguntar: Enfim, o que Efland defende? Explorar as diferenças, desde que não atinjam aquilo que chama de "alma"? Uma "exploração" superficial da diferença a título de curiosidade? O que devemos supor?

Além disso, Efland (2005) trata as mídias como detentoras de um poder total de alienação e seus produtos como se fossem portadores de um mesmo ideal, uma única ideologia que estaria sempre focada no consumo. Infelizmente, neste trabalho não há espaço para uma discussão mais aprofundada sobre esses preconceitos em relação às mídias. Contudo, acreditamos ser necessário atentar para o fato de que os produtos midiáticos "também participam dos conflitos sociais entre grupos concorrentes e veiculam posições conflitantes, promovendo às vezes forças de resistência e progresso" (KELLNER, 2001, p. 27).

Incluir imagens que vão além daquelas já consideradas artísticas pelo cânone eurocêntrico de críticos, museus, instituições educacionais e galerias, ou seja, do mercado internacional de arte, torna-se parte do processo de questionamento dos limites elitistas nos quais se protegeu uma prática mais ortodoxa da arte-educação. Discutir diferença cultural deve implicar localizar historicamente o discurso artístico para relativizar seus cânones e suas fronteiras. Contudo, se a inclusão de novos objetos de análise é bastante importante, é necessário que tal inclusão venha acompanhada de uma visão onde o conservadorismo institucional também seja posto em questionamento. Do contrário, cairíamos, apenas, num "acrescentar" irrefletido, e, talvez, irresponsável.

\section{Diferentes interpretações ou Mais do que imagens diferentes, sentidos diferentes...}

Cremos ainda que a inclusão da diferença na sala de aula pode se dar de outra forma além da adição de imagens outras ou imagens produzidas pelo "outro". A diferença torna-se importante para a arte-educação pós-moderna e para a Cultura Visual na medida em que a interpretação dos significados de uma obra deixa de se basear nas características formais ou na intenção do autor. Isso acontece em decorrência de uma abordagem que dá centralidade à noção de cultura.

Uma abordagem tradicional sobre como as imagens transmitem significados é a perspectiva que almeja explicar o poder estético das obras de arte com base na simples análise das características da obra, ou seja, suas relações formais e aspectos estilísticos. Para a arte-educação pós-moderna e a Cultura Visual, tal abordagem é equivocada ao desconsiderar que todo critério de análise estética é em si uma construção cultural, um 
regime discursivo, relacionado a um contexto específico, nunca universal (EFLAND, 2005, p. 179; MARTINS, 2007, p. 27).

Como afirma Martins (2007, p. 27), outra abordagem que merece questionamento é aquela segundo a qual o significado estaria condicionado, determinado, pela própria intenção do autor da obra, daquele que a cria, que a enuncia ou processa. Essa perspectiva romântica transformou a produção em momento hegemônico que promoveu e estabeleceu o papel individualista de auto-expressão para a arte. Contudo, ela desconsidera que todos nós precisamos levar em conta os mapas culturais que já são partilhados em sociedade se quisermos comunicar nossas idéias. Por isso, uma produção nunca seria algo exclusivamente autônomo, privado. Ninguém é dono dos significados também no sentido de que ninguém tem completo domínio sobre seus fluxos, sobre as interpretações de diferentes pessoas em diferentes contextos.

Ambas as abordagens desconsideram a diversidade de interpretações que os objetos artísticos permitem/possibilitam. Mas as propriedades objetivas e materiais da imagem e a intenção do autor não impedem esta variedade de leituras/interpretações. São abordagens que perpetuam a idéia de que o campo artístico é uma ilha autônoma, independente, separada dos demais aspectos da vida social cotidiana, que supõe ser uma cápsula asséptica de cultura, não considerando que todo critério estético é específico a um contexto, que são construções, regimes discursivos (MARTINS, 2007). Em paralelo, isso se reflete negativamente também na exclusão de artistas e trabalhos que fogem ou não se enquadram nas diretrizes do cânone hegemônico. Essa situação provoca a perda da oportunidade de se pensar sobre o papel social da arte (MARTINS, 2007, p.26). Para Efland (2005) e Martins (2007) não se trata simplesmente de representar a realidade, mas da construção de realidades.

Segundo Martins (2007), para compreender os significados das imagens, o campo da Cultura Visual deixa em segundo plano a imagem em si e a intenção do criador. Seu foco se orienta para a visualidade, ou seja, o olhar, não enquanto percepção mecânica, mas em sua dimensão cultural. "As imagens mudam de significado quando muda o entorno ou o contexto em que são veiculadas" (2007, p. 28). Ou seja, as interpretações serão sempre plurais, desde que sempre sejam plurais as referências e pressupostos culturais que condicionaram a experiência do olhar. 
Mesmo a imagem mais familiar, portanto, pode ser utilizada para tratar da diferença. Toda imagem tem um "caráter promíscuo" (MARTINS, 2007, p. 28), porque seus sentidos são geridos sob forças de diferença. Contudo, há a necessidade de não se satisfazer/conter com a simples constatação da diversidade de significados. É preciso que haja o incentivo para o questionamento sobre o porquê de alguns sentidos tornarem-se compartilhados, tornarem-se hegemônicos, e outros não. Isso pressupõe uma ênfase nos questionamentos sobre a influência das estruturas de poder nas práticas culturais.

\section{Diferentes condutas ou Do relativismo à ação ou à apatia}

A consciência gerada pela discussão sobre a diferença cultural de que todo sentido é uma construção humana e por isso relativo a contextos históricos específicos e, portanto, contingente, pode provocar, e frequentemente o faz, apatia, pessimismo, cinismo e até mesmo mutismo. Como agir, o que fazer, se tudo é ideológico? Como pensar a educação diante desse fato? O que podemos falar? Podemos falar pelos outros? Estas são questões com as quais se entra em conflito constantemente, pois ainda não temos respostas adequadas/convincentes para elas. Porém gostaríamos de discutir o modo como jagodzinski e Efland enfrentam estas questões.

Para o primeiro "embora a ideologia já esteja em ação em tudo aquilo que é experimentado como 'realidade', a tensão que mantém viva a crítica da ideologia precisa, no entanto ser mantida" (JAGODZINSKI, 2005, p. 661). Isso se justifica para este autor, pois, caso contrário, sem este esforço, também nos tornaríamos responsáveis pela manutenção das hegemonias racistas. Efland (2005) assume que cada vez há mais dificuldade e se ampliam conflitos para selecionar os conteúdos a serem discutidos em sala de aula. Ainda assim, ele também defende a necessidade de não cairmos na paralisia tipicamente pós-moderna. Para ele, temos o desafio de nos utilizarmos da crítica pós-moderna, mas, sem nos esquecermos de defender "os ideais democráticos" (2005, p.176).

Ambos os autores defendem, portanto, uma arte-educação como uma área de atuação global (EFLAND, 2005; JAGODZINSKI, 2005). Jagodzinski, embora reconheça a posição de autores como Jean-François Lyotard, que é contra qualquer pretensão de se construir grandes narrativas, defende que é preciso considerar que nos encontramos atualmente em um mundo globalizado, no qual precisaríamos agir para defender certos ideais universais. Ele se posiciona da seguinte maneira:

Isso significa um currículo num cenário planetário, destinado ao futuro que nossas crianças herdarão. Said (1992) refere-se ao conceito de "cosmopolitismo" (p.30) que para ele significa situar textos culturais (visuais e literários) num contexto que os abra às 
possibilidades de reconhecer a globalização das aspirações humanas universais democráticas de justiça, igualdade, liberdade e independência para todos, isto é, uma cidadania planetária na qual o imperialismo, nas suas formas pós-coloniais, o patriarcado, os problemas ecológicos, as distinções de classes forjadas pelo capitalismo transnacional e os direitos de preferência sexuais permaneçam em evidência na pauta educacional. Eu chamaria isso de uma educação de um habitante global. (JAGODZINKI, 2005, p. 684)

Efland faz proposta ainda mais audaciosa. Propõe, baseando-se na noção de ordem social tripla de Rudolph Steiner, a necessidade da construção de um novo modelo de sociedade. Destacamos neste modelo o que Efland (2005) chama de "esfera espiritual-cultural", uma instituição que seria responsável por fazer emergir uma "moralidade comum" ( $p$. 185).

Consideramos importante a posição desses autores na medida em que nos fazem pensar sobre nossa responsabilidade diante do contexto global das diferenças e das desigualdades. Entretanto, mantemos desconfiança especialmente quando se fala na construção de "uma moralidade comum" como faz Efland. Ainda mais porque o autor pouco especifica sobre a forma como se estabeleceria esta construção.

No livro A Idéia de Cultura, Terry Eagleton (2005) discute a idéia de uma cultura comum opondo as opiniões de T. S. Eliot às de Raymond Williams. Enquanto o primeiro autor propõe uma cultura comum em termos de conteúdo, todos pensando da mesma forma de acordo com o prescrito por alguns intelectuais, o segundo, propõe que a característica comum seria sua forma política. Para Williams, ainda segundo Eagleton (2005), se exigiria "uma ética de responsabilidade comum, plena participação democrática em todos os níveis da vida social, incluindo a produção material, e o acesso igualitário ao processo de criação da cultura" (p. 172). Nesse sentido, se T. S. Eliot almejava apagar as diferenças culturais, Williams aproveita-se dos conflitos que a diferença implica instrumentalizando-a para uma democracia socialista. Perguntamo-nos, então, com qual desses dois autores Efland se engaja ao falar de uma moralidade comum. Afinal: Quem seria responsável por construir essa moralidade? Um conjunto de normas seria criado e então imposto a todos? Qual seria o espaço para a diferença cultural nessa sociedade utópica? São questões que não ficam claras no texto de Efland e que permanecem vagas para nós.

\section{Inquietações}

O conceito de diferença é ideia chave para a educação da cultura visual. Contudo, à medida em que nos tornamos alertas para a variedade de significados que este conceito 
pode excitar em nossas interpretações, deve pesar em nossos ombros a responsabilidade de discutirmos em profundidade algumas questões. Afinal, a que sentidos nos referirmos quando diariamente falamos em diferença? Que sentidos estamos e devemos considerar? Como discuti-los? Que diferença é essa que desejamos? Qual o valor da diferença? Qual deve ser nossa conduta diante dela?

Enfrentar às últimas conseqüências tais questões, embora elas pareçam simples e a primeira vista inofensivas, pode nos levar a enfrentar os pressupostos nos quais muitos profissionais ainda se apóiam. As dúvidas sobre a legitimidade das fronteiras em que ainda se isola o campo artístico e sobre a autoridade de uma elite de "especialistas" para interpretar os significados das imagens que povoam nosso mundo são apenas algumas das conseqüências destas perguntas. Muitas respostas já estão em jogo nas discussões teóricas, mas a quem interessam? E nossas práticas, consideram os conflitos que o tema da diferença promove? Nossas respostas conduzirão à inclusão democrática e ativa da maioria hoje excluída ou, por fim, servirão à manutenção de grupos hegemônicos?

\section{Referências}

CANCLINI, Nestor Garcia. Diferentes, Desiguais e desconectados. RJ: UFRJ, 2005.

EAGLETON, Terry. A idéia de cultura. São Paulo: Editora UNESP, 2005.

EFLAND, Arthur. Cultura, sociedade, arte e educação num mundo pós-moderno. IN: BARBOSA, Ana Mae (Org.); Guinsburg, J. (Org.). O Pós-Modernismo. São Paulo: Perspectiva, 2005.

HALL, Stuart. A questão multiculturalista. In: Da Diáspora: identidades e mediações culturais. Belo Horizonte: UFMG, 2006.

JAGODZINSKI, jan. As negociações da diferença: arte educação como desfiliação na era pós-moderna. IN: BARBOSA, Ana Mae (Org.); Guinsburg, J. (Org.). O Pós-Modernismo. São Paulo: Perspectiva, 2005.

KELLNER, Douglas. A cultura da mídia. Bauru, São Paulo: EDUSC, 2001.

MARTINS, Raimundo. A cultura visual e a construção social da arte, da imagem e das práticas do ver. In: OLIVEIRA de OLIVEIRA, Marilda (Org.). Arte, Educação e Cultura. Santa Maria: Editora UFSM, 2007, p.19-40.

MATHIAS, José Ronaldo Alonso. Diferença e identidade: sentidos em construção. 2006. 191 f. Tese (Doutorado em Comunicação social), ECA/USP, São Paulo.

MCLAREN, Peter. Multiculturalismo crítico. São Paulo: Cortez:Instituto Paulo Freire, 2003.

SEMPRINI, Andréa. Multiculturalismo. Bauru, SP: EDUSC, 1999.

SHOHAT, Ella; STAM, Robert. Crítica da imagem eurocêntrica: Multiculturalismo e Representação. Rio de Janeiro: Cosac \& Naify, 2006. 